\title{
ANALISIS KEBUTUHAN KAYU BAKAR UNTUK PEMBAKARAN BATU BATA DI KECAMATAN RUMBAI, KOTA PEKANBARU
}

\author{
Enny Insusanty, Emy Sadjati, Ambar Tri Ratnaningsih \\ Staff Pengajar Fakultas Kehutanan Universitas Lancang Kuning \\ Jln. Yos Sudarso Km. 8 Rumbai Pekanbaru Riau \\ Email: ennyinsusanty@unilak.ac.id,emy_mnhunilak@gmail.com_dan ambar_trn@yahoo.com
}

\begin{abstract}
This study aims to find out the needs of wood for brick making in Kecamatan Rumbai and to analyze the revenue and the contribution of the cost of wood fuel for brick making. The method used in this study is the survey method in the form of interviews to brick making business owners and field observation and calculate the needs of firewood and brick production. The average brick production of each factory is 65,000 bricks per 2 months with the amount of firewood required $20.5 \mathrm{~m}^{3}$ so for the year it takes $123 \mathrm{~m}^{3}$. For all existing factories in Muara Fajar village with the number of 80 factories is required bricks as much as $9,840 \mathrm{~m}^{3}$ per year. Components of fuel wood as fuel reached $34.9 \%$ of production costs with total cost of production (2 months) is Rp $11,448,750$ and the profit earned by craftsmen is $\mathrm{Rp} 1,518,750$.
\end{abstract}

Keyword: firewood, Brick, Cost of fuel wood

PENDAHULUAN

Di Indonesia kayu merupakan biomassa yang sudah lama dikenal oleh masyarakat dan merupakan sumber energi terbarukan. Menurut Maharjoeno (2005), potensi biomassa yang bersumber dari kayu antara lain : limbah penggergajian kayu, limbah plywood dan limbah logging. Selain ketersediaannya cukup banyak di Indonesia, biomassa kayu juga cenderung tidak menyebabkan dampak negatif pada lingkungan (Alkarami, 2007). Sumber energi biomassa mempunyai beberapa kelebihan antara lain merupakan sumber energi yang dapat diperbaharui (renewable) sehingga dapat menyediakan sumber energi secara

berkesinambungan(suistainable).

Sebelum mengenal bahan bakar fosil, manusia sudah menggunakan biomassa sebagai sumber energi, misalnya dengan menggunakan kayu untuk menyalakan api unggun. Sejak manusia beralih pada minyak, gas bumi atau batu bara untuk menghasilkan tenaga, penggunaaan biomassa tergeser dari kehidupan manusia (Welle, 2009). Kayu bakar menjadi alternatif pilihan yang banyak diupayakan oleh masyarakat untuk kebutuhan energi 
rumah tangga pedesaan dan industri kecil karena lebih mudah diperoleh dan harganya relatif murah.

Pembuatan batu bata yang ada disekitar Kecamatan Rumbai merupakan salah satu industri kecil yang memanfaatkan kayu bakar untuk proses pemanggangan batu bata. Industri rumah tangga di perdesaan yang memberikan andil dalam menciptakan lapangan pekerjaan dan peningkatan pendapatan rumah tangga salahsatunya adalah industri rumah tangga batu bata. Industri rumah tangga batu bata merupakan industri rumah tangga yang memanfaatkan bahan baku berupa tanah dan diolah dengan proses pengolahan yang sederhana.

Adanya usaha industri batu sebagai penyuplai bahan bangunan yang ada di Kota Pekanbaru sebagai salah satu kota yang mempunyai perkembangan yang pesat dari segi bangunan sehingga usaha ini dari segi peluang pasar sangat baik sejalan dengan perkembangan pembangunan. Pembuatan batu bata yang diawali dari merancah lumpur, mencetak, melangsir dan mengeringkan sampai pada tahap pembakaran akan menyerap tenaga kerja karena jenis industri ini merupakan usaha padat karya.
Pada tahap pembakaran dibutuhkan bakan bakar berupa kayu bakar yang jumlahnya cukup banyak. Kebutuhan kayu bakar merupakan bagian penting keberlangsungan usaha batu bata dan menjadi salah satu komponen biaya yang harus diluarkan. Pemanfaatan kayu bakar ini akan memberikan nilai kayu yang apalagi jika bersumber dari limbah atau jenis kayu yang diperuntukkan untuk kayu bakar.

Kebutuhan kayu bakar untuk proses pembuatan batu bata diperoleh dari hutan ataupun kebun masyarakat yang ada disekitar Kota Pekanbaru maupun diluar Kota Pekanbaru. Tingkat kebutuhan kayu bakar ini cukup besar karena merupakan sumber energi utama dalam pembuatan batu bata. Ketersediaan kayu sangat menentukan keberlangsungan usaha ini. Dengan semakin langkanya ketersediaan kayu maka dapat menyebabkan peningkatan harga kayu sehingga biaya pembuatan batu bata akan semakin besar.

Berdasarkan uraian yang sudah dipaparkan di atas, peneliti tertarik untuk melakukan penelitian dengan judul "Analisis kebutuhan kayu bakar untuk pembuatan batu bata di Kecamatan Rumbai Pekanbaru" Adapun tujuan dari penelitian ini adalah untuk mengetahui 
kebutuhan kayu untuk pembuatan batu bata di kecamatan Rumbai dan menganalisa pendapatan usaha batu bata dan kontribusi biaya dari bahan bakar kayu pembuatan batu bata.

\section{METODE PENELITIAN}

\section{Lokasi dan Waktu Penelitian}

Penelitian ini akan dilaksanakan mulai Oktober 2016 hingga Desember 2017 di Desa Muara Fajar yang merupakan sentra pembuatan batu bata di Kecamatan Rumbai Kota Pekanbaru

\section{Alat Dan Bahan}

Alat dan bahan yang digunakan adalah: kamera digital, seperangkat komputer, kalkulator, kuisioner, alat tulis, alat perekam

\section{Objek Penelitian}

Objek dalam penelitian ini adalah pemilik usaha pembuatan batu bata yang ada di Kecamatan Rumbai. Penentuan sampel dilakukan secara purposive sampling sebanyak $10 \%$ dari total populasi yaitu 80 bedeng sehingga diambil 8 orang pemilik bedeng. Kepada pemilik usaha akan dilakukan wawancara mengenai kebutuhan terhadap energi kayu bakar, jumlah kayu bakar, jenis, sumber kayu bakar dan harga. Selain itu juga ditanyakan mengenai pendapatan dan biaya dalam usaha pembuatan batu bata. Untuk observasi lapangan dilakukan kesetiap lokasi pembuatan batu bata dan menghitung kebutuhan kayu dan produksi batu-bata per bulan.

\section{Metode Pengumpulan Data}

Adapun jenis data yang terdapat dalam penelitian ini adalah:

1. Data Primer

Data primer merupakan data yang diperoleh langsung melalui wawancara langsung dan observasi lapangan dengan masyarakat pemilik usaha menggunakan daftar pertanyaan (kuesioner) yang telah disusun sesuai dengan tujuan penelitian. Data primer meliputi; jumlah kebutuhan kayu, sumber , jenis kayu, serta komponen biaya dalam pengelolaan usaha.

2. Data Sekunder

Data sekunder di kumpulkan melalui pencatatan yang meliputi kondisi umum lokasi penelitian, potensi lokasi penelitian, data umum terdapat di instansi desa, kecamatan dan lembaga-lembaga yang berkaitan serta harga produk di pasar. 
Analisis Data

Pengolahan data yang diperoleh dari pengumpulan data dari lapangan baik berupa data primer ataupun data sekunder serta hasil kusioner dianalisis secara deskriptif kualitatif. Adapun Pengolahan data dilakukan dengan rumusan sebagai berikut :

$$
\mathrm{JT}=\mathrm{BT} \times \mathrm{KY} \times \mathrm{F}
$$

Keterangan:

JT = Jumlah kebutuhan kayu bakar setahun

BT = Jumlah tungku pembakaran $\mathrm{KY}=$ Rata-rata kebutuhan kayu bakar per pembakaran

$\mathrm{F}=$ Frekuensi pembakaran setiap tahun Untuk mengetahui nilai pendapatan dari usaha pembuatan batu bata ini dilakukan dengan menggunakan. Besarnya penerimaan yang diperoleh oleh pemilik usaha dapat dipengaruhi olehbesarnya produksi dan harga jual dari yang dihasilkan. Untuk mengetahui besarnya penerimaan, perhitungan dilakukan melalui rumusan sebagai berikut :

$\mathrm{TR}=\mathrm{Y} . \mathrm{Py}$

dimana :

$\mathrm{TR}=$ PenerimaanTotal/TotalRevenue (Rp)

$\mathrm{Y}=$ Jumlah produksi unit (buah)

Py = Harga unit (Rp/buah)
Dari hasil perhitungan biaya produksi dan penerimaan, selanjutnya dapat diketahui besarnya keuntungan yang diperoleh. Untuk mengetahui besarnya keuntungan secara matematis dapatdituliskan sebagai berikut :

$N P=T R-T C$

dimana

NP = Penerimaan bersih Keuntungan / laba $(\mathrm{Rp})$

TR=TotalPenerimaan /TotalRevenue (Rp)

$\mathrm{TC}=$ BiayaTotal $/$ Total Cost $(\mathrm{Rp})$

Kontribusi biaya dan nilai kayu bakar dalam usaha pembuatan batu bata dengan cara biaya dari bahan bakar kayu dibagi dengan jumlah total biaya dikalikan dengan seratus persen atau dapat ditulis dengan rumus:

$$
\% \mathrm{KY}=\frac{\mathrm{BKY}}{\mathrm{BT}} \times 100 \%
$$

Ket:

$\% \mathrm{KY}$ : Persentase kontribusi biaya kayu bakar (persen)

BKY : Biaya kayu bakar (Rp)

BT : Biaya Total (Rp)

Hasil perhitungan kebutuhan kayu dari pemilik usaha pembuatan batu-bata berdasarkan jumlah, jenis dan sumber kayu maka perlu disesuaian 
dengan ketersediaan kayu bakar yang ada sehingga usaha ini dapat terus berlanjut. Dalam usaha pembuatan batu bata, kayu bakar adalah salah satu komponen biaya variabel yang dapat berubah sesuai dengan produksi dan menjadi sumber energi utama dalam kegiatan pembakaran sehingga biaya yang dikeluarkan menjadi salah satu yang ingin diketahui untuk mengetahui nilai kayu bakar sebagai salah satu hasil hutan berupa sumber energi.

\section{HASIL DAN PEMBAHASAN}

\section{Proses Pembuatan Batu Bata}

Dari hasil penelitian diperoleh data tentang jumlah pembuat batu bata yang ada di Desa Muara Fajar yang membakar sebanyak 80 pengrajin yang tersebar di beberapa lokasi. Dari 80 tersebut diambil $10 \%$ yaitu delapan tungku pembakaran untuk mengetahui rata-rata jumlah batu ara dan frekensi pembakaran. Jumlah dan frekuensi setiap kali pembakaran pada tiap-tiap tungku pembakaran dapat dilihat pada tabel berikut:
Tabel 1. Kebutuhan Kayu Bakar

\begin{tabular}{|c|c|l|c|c|}
\hline $\begin{array}{l}\mathbf{N} \\
\mathbf{0} \\
\mathbf{0}\end{array}$ & $\begin{array}{l}\text { Jumlah } \\
\text { batu } \\
\text { bata }\end{array}$ & $\begin{array}{l}\text { Frekuensi } \\
\text { Pembakaran }\end{array}$ & $\begin{array}{l}\text { Kebutuhan } \\
\text { kayu bakar } \\
\text { (m3) }\end{array}$ & $\begin{array}{l}\text { Kebutuhan } \\
/ \mathbf{1 0 . 0 0 0}\end{array}$ \\
\hline 1 & 70.000 & 2 bulan & 24 & 3,42 \\
\hline 2 & 120.000 & 2 bulan & 32 & 2,66 \\
\hline 3 & 40.000 & 2 bulan & 12 & 3,00 \\
\hline 4 & 50.000 & 2 bulan & 16 & 3,2 \\
\hline 5 & 60.000 & 2 bulan & 20 & 3,3 \\
\hline 6 & 40.000 & 2 bulan & 12 & 3,00 \\
\hline 7 & 70.000 & 2 bulan & 24 & 3,24 \\
\hline 8 & 70.000 & 2 bulan & 24 & 3,42 \\
\hline & 65.000 & & 20,5 & 3,15 \\
\hline
\end{tabular}

Kebutuhan kayu bakar untuk pembakaran bervariasi untuk setiap tungku pembakaran yaitu 40.000 batu bata adalah 3 truk kayu bakar sementara untuk tungku pembakaran yang lain membutuhkan 7 truk kayu bakar untuk 100.000 batu bata dimana harga kayu bakar per truk adalah Rp 1.000.000,- Pembakaran yang dilakukan per dua bulan setiap tungku pembakaran sehingga dalam 1 tahun dilakukan sebanyak 6 kali pembakaran yang membutuhkan rata-rata $20,5 \mathrm{~m} 3$ untuk 65.000 batu bata atau $3,15 \mathrm{~m} 3$ per 10.000 batu bata.

Dengan frekuensi pembakaran 2 kali sebulan maka setiap tahun dilakukan 6 kali pemakaran batu bata. Sehingga dibutuhkan kayu bakar sekitar 123 m3 kayu bakar pertahun untuk setiap tungku pembakaran. Adapun jumlah bedeng batu bata dengan tungku pembakaran saat ini di Kelurahan Muara 
Fajar terdapat 80 buah sehingga dalam tahun diperlukan 9.840 m3 kayu bakar. Dengan jumlah kebutuhan kayu bakar yang cukup besar setiap tahun maka ketersediaan kayu bakar menjadi hal yang menentukan keberlangsungan usaha.

Kayu bakar yang digunakan oleh pengrajin terdiri dari kayu campuran yang di dominasi oleh kayu akasia sekitar $80 \%$. Adapun jenis kayu yang diperoleh saat ini adalah : akasia, jengkol, karet, rambutan dan mangga. Jenis kayu karet yang digunakan hanya $10 \%$ sedangkan sisanya dari jenis lain. Pada dasarnya semua jenis kayu diterima oleh pengrajin tapi kayu akasia paling banyak karena di riau banyak terdapat kayu ini selain itu juga memiliki nilai kalor yang baik. Sebagian pengrajin juga ada yang memanfaatkan kayu dari sisa dari saw mill namun jumlahnya terbatas karena harganya per pick up lebih murah yaitu $\mathrm{Rp} 250.000$ namun panas yang dikeluarkan lebih sedikit sehingga kayu saw mill cepat habis. Sumber kayu yang ada diperoleh dari daerah minas dan perawang sebagian juga ada dari Kabupaten Kampar.
Tabel. 2 Produktifitas Tenaga Kerja

\begin{tabular}{|c|c|c|c|}
\hline No. & $\begin{array}{c}\text { Jumlah batu } \\
\text { bata }\end{array}$ & $\begin{array}{c}\text { Jumlah } \\
\text { Tenaga } \\
\text { kerja }\end{array}$ & $\begin{array}{c}\text { Produktifita } \\
\text { s }\end{array}$ \\
\hline 1 & 70.000 & 2 & 583 \\
\hline 2 & 120.000 & 5 & 400 \\
\hline 3 & 40.000 & 2 & 333 \\
\hline 4 & 50.000 & 2 & 416 \\
\hline 5 & 60.000 & 2 & 500 \\
\hline 6 & 40.000 & 2 & 333 \\
\hline 7 & 70.000 & 3 & 388 \\
\hline 8 & 70.000 & 3 & 388 \\
\hline $\begin{array}{c}\text { Rata } \\
\text {-rata }\end{array}$ & 65.000 & 2,62 & 417,62 \\
\hline
\end{tabular}

Produktifitas pekerja yang melakukan pekerjaan pencetakan batu bata pervariasi dari 333 batu bata/hari sampai dengan 583 batu bata/hari. Pekerjaan pencetakan batu bata dilakukan secara manual dan pada umumnya dilakukan oleh perempuan. Tenaga kerja laki-laki biasanya melakukan pekerjaan yang lebih berat seperti pengaduk, mengangkat, membakar batu bata. Namun sebagian tenaga kerja laki-laki juga ikut terlibat langsung. Pekerjaan pembuatan batu bata ini dilakukan per keluarga seperti suami istri yang dibantu oleh anakanaknya. Biasanya istri melakukan pekerjaan rumah tangga di pagi hari dan kemudian baru mengerjakan pencetakan batu bata. Untuk upah pencetakan ini dapat pula dibayarkan dengan sistem borongan yaitu $R p$ 50.000 per 1000 batu bata. 
Analisis Usaha Pembuatan Batu Bata

Analisis usaha pembuatan batu bata di Kelurahan Muara Fajar untuk 1 kali produksi (2 bulan). Analisis ini dimulai dengan mentabulasikan semua komponen produksi yang dapat dikategorikan biaya tetap dan biaya variabel. Pembuatan batu bata ini dilakukan dengan sistem bagi hasil yaitu $70 \%$ untuk pengrajin dan $30 \%$ untuk pemilik tempat usaha.

Tabel 3. Biaya Penyusutan Bangunan

\begin{tabular}{|l|l|c|r|}
\hline No & Jenis & $\begin{array}{l}\text { Investasi } \\
\text { total (Rp) }\end{array}$ & $\begin{array}{l}\text { Penyusutan } \\
\text { (2 bulan) Rp }\end{array}$ \\
\hline 1 & Bedeng & 25.000 .000 & 375.000 \\
\hline 2 & $\begin{array}{l}\text { Tungku } \\
\text { bakar }\end{array}$ & 25.000 .000 & 375.000 \\
\hline & Jumlah & & 750.000 \\
\hline
\end{tabular}

Hasil wawancara dengan pemilik dan pengrajin batu bata untuk biaya investasi bangunan yang terdiri dari dua bentuk yaitu bedeng yang digunakan untuk cetak bata sekaligus menjemur dan tungku pembakaran. Adapun biaya untuk kedua bangunan ini adalah $\mathrm{Rp}$ 50.000.000,- dengan umur teknis 10 tahun sehingga biaya penyusutan adalah Rp 4.500.000/tahun. Untuk per produksi maka biaya penyusutan dari bangunan adalah Rp 750.000. Adapun biaya bangunan ini dikeluarkan oleh pemilik usaha sedangkan pengrajin batu bata memberikan bagi hasil dari penjualan batu bata yang dilakukan sebesar $30 \%$.

Tabel 4. Biaya Penyusutan Alat

\begin{tabular}{|l|l|r|r|}
\hline No & Jenis & \multicolumn{1}{|c|}{$\begin{array}{l}\text { Investasi } \\
\text { total (Rp) }\end{array}$} & $\begin{array}{l}\text { Penyusutan } \\
\text { (2 bulan) } \mathbf{R p}\end{array}$ \\
\hline 1 & Gerobak & 300.000 & 11.250 \\
\hline 2 & Cangkul & 140.000 & 5.250 \\
\hline 3 & Meja & 200.000 & 15.000 \\
\hline 4 & $\begin{array}{l}\text { Kayu } \\
\text { cetakan }\end{array}$ & 30.000 & 2.250 \\
\hline 5 & $\begin{array}{l}\text { Gerobak } \\
\text { kayu }\end{array}$ & 200.000 & 15.000 \\
\hline & Jumlah & & 48.750 \\
\hline
\end{tabular}

Peralatan yang digunakan oleh pengrajin terdiri dari gerobak, cangkul, meja, kayu cetakan dan gerobak kayu. Pembuatan batu bata masih dilakukan secara manual sehingga peralatan yang digunakan masih sangat sederhana. Untuk biaya peralatan ini setiap kali produksi diperlukan sebanyak $\mathrm{Rp}$ 48.750. Biaya ini dikeluarkan oleh pengrajin dalam memproduksi batu bata.

\section{Biaya Penggunaan Bahan Baku}

Bahan baku yang digunakan pada proses pembuatan batu bata adalah tanah, serbuk kayu, dan kayu bakar. Adapun rincian biaya dapat dilihat pada tabel.5 
Tabel 5. Biaya Bahan Baku

\begin{tabular}{|l|l|l|l|}
\hline No & $\begin{array}{l}\text { Bahan } \\
\text { Baku }\end{array}$ & Jumlah & Biaya (Rp) \\
\hline 1 & $\begin{array}{l}\text { Serbuk } \\
\text { kayu }\end{array}$ & 1 pick up & 175.000 \\
\hline 2 & Kayu bakar & $20,5 \mathrm{~m}^{3}$ & 4.000 .000 \\
\hline
\end{tabular}

Bahan baku yang diperlukan untuk mencetakan batu bata memerlukan biaya Rp 5.175.000 dimana komponen terbesar adalah kayu bakar sebagai bakan bakar untuk tungku pembakaran. Kebutuhan kayu yang cukup besar ini digunakan pada proses pembakaran dengan durasi 3 hari 3 malam (72 jam) tanpa berhenti untuk memperoleh batu bata yang baik. Bahan baku lain yang yang digunakan adalah air namun tidak menjadi komponen biaya pada analisis ini.

\section{Biaya Tenaga Kerja}

Biaya tenaga kerja yang dilakukan untuk membuat batu bata dilakukan per Rumah tangga dimana satu bedeng adalah 1 keluarga. Pekerjaan yang berat biasanya dilakukan oleh laki-laki sedangkan untuk mencetak dilakukan oleh perempuan dan juga dibantu oleh anaknya. Upah tenaga kerja dapat dilihat pada Tabel 6
Tabel 6. Biaya Tenaga Kerja

\begin{tabular}{|l|l|r|}
\hline No & Pekerjaan & \multicolumn{1}{|c|}{ Biaya Upah (Rp) } \\
\hline 1 & Mencetak & 3.250 .000 \\
\hline 2 & Mengaduk & 325.000 \\
\hline 3 & Mengangkat & 650,000 \\
\hline 4 & Sewa Kerbau & 975.000 \\
\hline 5 & Pembakaran & 300.000 \\
\hline \multicolumn{2}{|l}{ Jumalah } & 5.500 .000 \\
\hline
\end{tabular}

Biaya upah terbesar dalam upah adalah biaya cetak batu bata kerena dilakukan secara manual dan memakan waktu cukup lama yaitu sekitar 2 bulan sambil dijemur dan kemudian disusun ketungku pembakaran.

Tabel 7. Biaya Pemasaran Batu Bata

\begin{tabular}{|c|l|l|c|}
\hline $\begin{array}{c}\mathbf{N} \\
\mathbf{0}\end{array}$ & Uraian Biaya & \multicolumn{1}{|c|}{ Biaya } & $\begin{array}{l}\text { Biaya } \\
\text { Upah } \\
\text { (Rp) }\end{array}$ \\
\hline 1 & $\begin{array}{l}\text { Biaya } \\
\text { bongkar muat }\end{array}$ & $\begin{array}{l}100.000 / 20 . \\
000 \text { batu } \\
\text { bata }\end{array}$ & 325.000 \\
\hline 2 & $\begin{array}{l}\text { Biaya } \\
\text { pengangkuta } \\
\text { n }\end{array}$ & $\begin{array}{l}200.000 / 20 . \\
000 \text { batu } \\
\text { bata }\end{array}$ & 650.000 \\
\hline & Jumlah & & 975.000 \\
\hline
\end{tabular}

Biaya yang dikeluarkan untuk kegiatan pemasaran terdiri dari dua komponen yaitu biaya mongkar buat batu bata kedalam truk yang biasanya dilakukan oleh 2 orang dan biaya pengakutan yang merupakan sewa mobil. Penjualan batu bata biasanya dapat menggunakan mobil truk ataupun pick up. Batu bata langsung diambil dari tungku pembakaran oleh pembeli dengan menggunakan perantara. 
Tabel 8. Total Biaya Tetap dan Tidak Tetap Usaha Batu Bata

\begin{tabular}{|c|l|r|}
\hline No & \multicolumn{1}{|c|}{ Uraian } & \multicolumn{1}{|c|}{$\begin{array}{c}\text { Total biaya } \\
\text { produksi (2 } \\
\text { bulan) }\end{array}$} \\
\hline \multirow{4}{*}{$1 \quad \begin{array}{l}\text { Biaya penyusutan } \\
\text { bangunan }\end{array}$} & 750.000 \\
\cline { 2 - 3 } & $\begin{array}{l}\text { Biaya penyusutan } \\
\text { peralatan }\end{array}$ & 48.750 \\
\cline { 2 - 3 } & Biaya Tetap & $\mathbf{7 9 8 . 7 5 0}$ \\
\hline \multirow{4}{*}{2} & Biaya bahan baku & 4.175 .000 \\
\cline { 2 - 3 } & Biaya tenaga kerja & 5.500 .000 \\
\cline { 2 - 3 } & Biaya pemasaran & 975.000 \\
\cline { 2 - 3 } & Biaya Tidak tetap & $\mathbf{1 0 . 6 5 0 . 0 0 0}$ \\
\hline \multirow{2}{*}{$\begin{array}{l}\text { Total Biaya (Tetap + } \\
\text { Tidak tetap) }\end{array}$} & $\mathbf{1 1 . 4 4 8 . 7 5 0}$ \\
\hline
\end{tabular}

\section{Pendapatan}

Perhitungan pendapatan usaha pembuatan batu bata diperoleh dengan cara mengurangkan nilai jual keseluruhan produk dengan total biaya tetap dan total biaya tidak tetap yang dikeluarkan

Tabel 9. Pendapatan Usaha Batu Bata

\begin{tabular}{|l|l|l|l|}
\hline $\begin{array}{l}\text { Jenis } \\
\text { komoditi }\end{array}$ & $\begin{array}{l}\text { Jumlah } \\
\text { Produksi }\end{array}$ & $\begin{array}{l}\text { Harga } \\
\text { Jual } \\
\text { (Rp) }\end{array}$ & $\begin{array}{l}\text { Pendapatan } \\
\text { (Rp) }\end{array}$ \\
\hline Batu bata & 65.000 & 285 & 18.525 .000 \\
\hline
\end{tabular}

Produk yang dihasilkan hanya 1 jenis batu bata dengan jumlah 65.000 dengan tidak ada perbedaan kualitas walaupun pada saat pembakaran batu bata yang pada proses pembakaran berada pada bagian atas (istilah: pucuk) biasanya lebih rapuh. Harga jual batu bata bervariasi pada saat harga murah sekitar Rp 250.000 sd. Rp 260.000, namun pada waktu penelitian harga batu bata pada kondisi yang cukup tinggi yaitu Rp 320.000 sehingga nilai yang diambil merupakan harga rata-rata batu bata yaitu sebesar Rp 285.000. Untuk pembagian antara pemilik tempat dengan pengrajin maka dilakukan pembagian sebesar 70: 30 sehingga sharing pendapatan adalah :

\section{Tabel 10. Sharing Pendapatan Usaha Batu Bata}

\begin{tabular}{|l|l|r|}
\hline No & Uraian & Pendapatan (Rp) \\
\hline 1 & Pengrajin & 12.967 .500 \\
\hline 2 & Pemilik tempat & 5.557 .500 \\
\hline
\end{tabular}

Keuntungan yang diperoleh usaha pembuatan batu bata untuk 1 kali produksi adalah

$\mathrm{NP}=\mathrm{TR}-\mathrm{TC}$

$N P=R p 12.967 .500-R p 11.448 .750=$ Rp 1.518.750

Jika dikeluarkan biaya penyusutan bangunan karena biaya ini dibayarkan oleh pemilik tempat yaitu $\mathrm{Rp} 750.000$ maka keuntungan yang diperoleh oleh pengrajin menjadi Rp. 2.268.750 per sekali produksi

Kontribusi biaya kayu bakar terhadap total biaya adalah

$\% \mathrm{KY}=\frac{4000.000}{11448750} \times 100 \%=34,9 \%$

Dari perhitungan analisis biaya diperoleh bahwa biaya total yang dikeluarkan pada usaha pembuatan batu bata adalah sebesar Rp 
11.448.750 yang terdiri dari kompnen biaya tetap dan tidak tetap. Kayu bakar merupakan komponen dari biaya tidak tetap yang jumlahnya dapat berubah sesuai dengan jumlah produksi dari batu bata tersebut. Biaya yang dikeluarkan untuk 65.000 batu bata adalah sebesar Rp 4.000.000 yang merupakan biaya yang terbesar nomor dua setelah tenaga kerja yaitu 34,9\%. Tenaga kerja yang merupakan keluarga dan dikerjakan sendiri maka biasanya oleh pengrajin tidak dihitung atau tidak merasa dikeluarkan. Sehingga komponen terbesar yang harus dibayarkan langsung oleh pengrajin adalah kayu bakar yang juga tidak mudah didapat dan harganya dapat meningkat dan mempengaruhi pendapatan.

\section{KESIMPULAN DAN SARAN}

Kebutuhan kayu bakar untuk seluruh bedeng yang ada di Desa Muara Fajar dengan jumlah bedeng 80 buah sebanyak 9.840 m3 kayu bakar per tahun. Komponen kayu bakar sebagai bahan bakar mencapai 34,9\% terhadap biaya produksi dengan biaya total persekali produksi ( 2 bulan) adalah $\mathrm{Rp}$ 11.448.750 dan keuntungan yang diperoleh pengrajin adalah $\mathrm{Rp}$ 1.518.750.

\section{DAFTAR PUSTAKA}

Anonimous. 2004. "Wood Biomass for Energy". Techline. Forest Products Laboratory. http://www.fpl.fs.fed.us. Diakses pada 28-9-20017.

Alkarami 2007 Biomassa, Energi Masa Depan. http://aksarabumi.org.

Maharjoeno .2005. Energi Alternatif Pengganti BBM: Potensi Limbah Biomassa Sawit Sebagai Sebagai Sumber Energi Terbarukan. Lembaga Riset Perkebunan Indonesia. Jakarta.

Welle, D.2008. Biomassa Sebagai Sumber Energi Terbarukan. Sain dan Teknologi. http:///www.dwworld.dw/ article. Diakses pada 20 $11-2017$ 